\title{
The Finite Element Analysis of Tailings Dam Seepage
}

\author{
Cheng Peng, a, Shuang Chen²,b Wei Chen ${ }^{3, c}$ \\ ${ }^{1}$ University of South China, Hengyang City, Hunan Province, China \\ ${ }^{2}$ University of South China, Hengyang City, Hunan Province, China \\ 3University of South China, Hengyang City, Hunan Province, China \\ auscEmonk@126.com, b506014015@qq.com, c450137717@qq.com
}

\begin{abstract}
Keywords: tailings dam, seepage flow, infiltration line, the conventional drainage well, the radiation well.

Abstract. Among the many factors affecting the stability of tailings dam, the influence of seepage is very significant. In this paper, the seepage stability of a tailings dam at the accumulation profile elevation and the design elevation were analyzed by using 2D finite element. The results show that the infiltration line will overflow from the dam body when the dam is accumulated at the design elevation. Therefore, two different row seepage measures (traditional drainage and radiation wells) were used respectively to the tailings dam, the seepage stability of the tailings dam by taking two measures were analyzed, the drainage effect of two measures were compared. The results show that the radiation well is better emergency drainage facilities.
\end{abstract}

\section{Introduction}

Tailings dam is a special industrial building after discharge stockpiling beneficiation tailings or other industrial waste residue .Tailing reservoir have a lot of tailings and waste water, which is a dangerous source of man-made debris with high potential energy [1]. With the development of China's mining industry, the height and number of the tailings dam are constantly increasing, during the tailings reservoir area, the greatest risk is the dam-break accident, when it happen, it will cause a major event casualties, property damage and environmental pollution

There are many factors affect the stability of tailing, wherein the most significant effect is water[2]. In order to ensure the safe operation of the tailing dam, it should control the height of the infiltration line to make sure it does not happen seepage failure.In history,there were many tailings dam of unstable failure was caused by seepage failure[3].Therefore, the tailings dam of seepage analysis is very important.

Currently, the tailings dam of seepage analysis have three methods ,such as Theoretical calculation, physical simulation test and numerical simulation analysis .Since the numerical simulation of the finite element method can fully meet the constitutive relation and the environment can be simulated under a variety of conditions, so many scholars have used finite element software analysis tailings dam of seepage analysis. For example,ShaoJun Wang[4] use of MIDAS/GTS analysis tailings seepage in three dimensions; Xiaoxiao Ran[5]use ABAQUS analysis tailings dam in two dimensions and numerical stability;Under the different drainage capacity ,Hongde Wang[6] make numerical simulation with GeoStudio of the initial dam infiltration line.

In This paper, the different heights of the tailings dam seepage line was analysed by the finite element software, The results are compared and analyzed, and on the basis of height infiltration line ,the drainage measures is designed ,then analysis of these two ways of Traditional seepage drainage well and Radiation Well to find out which effect is best, at the time of the emergency discharge of seepage, the seepage measures was determined, which provide a theoretical basis for the protection of the safe operation of the tailings dam. 


\section{Engineering Situation}

A tailings dam is upstream and valley type tailings dam, the initial dam is permeable dam, the dam crest elevation is $105 \mathrm{~m}$, height is $20 \mathrm{~m}$, crest width is $4 \mathrm{~m}$, and crest axis length is $78.5 \mathrm{~m}$, the upstream and downstream slope ratio is $1: 2$, the tailings fill dam of slope ratio is $1: 3$, the final design of the tailings fill dam elevation is $175 \mathrm{~m}$, height is $90 \mathrm{~m}$, which belong to grade III tailings dam. At present, the tailings dam of fill dam crest elevation is $155 \mathrm{~m}$, and height is $70 \mathrm{~m}$.

\section{Numerical Simulation}

Material Partition and Calculation Parameter.According to Hongda $\mathrm{Xu}[7]$ and Zhenshi Guo[8], and so forth, study on the law of deposition tailings dam, Three kinds of materials, which are fine sang, tail silty sand and tail silt soil, were successively divided from beach deposited to the bottom of reservior,Calculation model of material partition coefficient and permeability as shown in Fig.1 and Table 1.

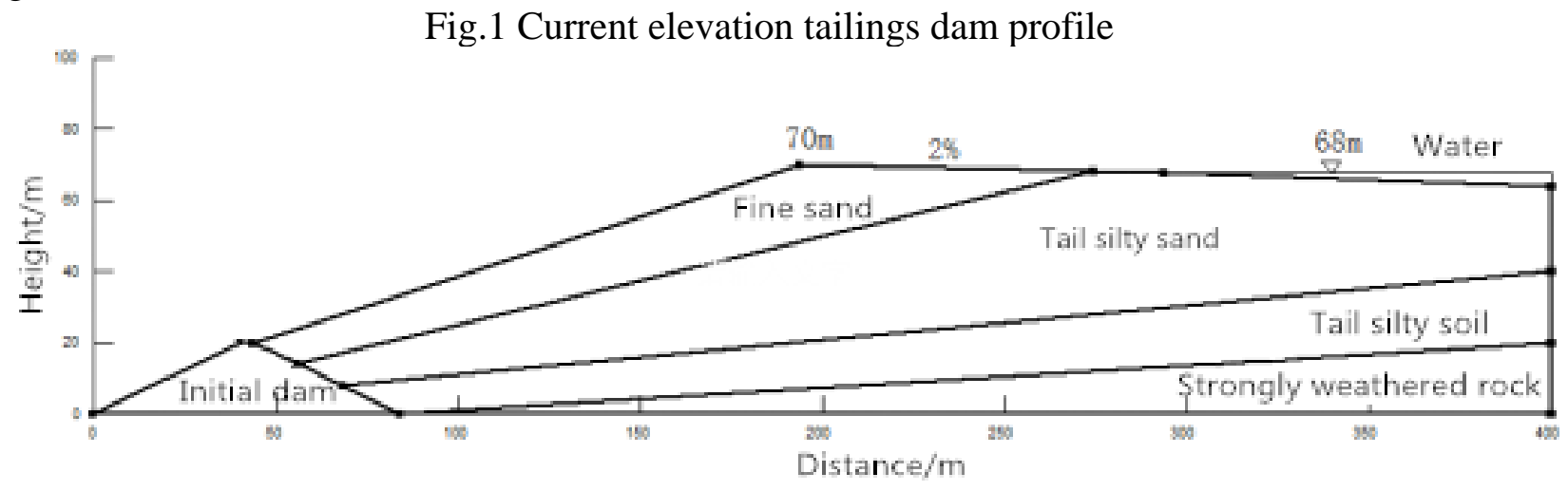

Table 1. Material permeability coefficient of dam body

\begin{tabular}{lccccc}
\hline Partition material & Initial dam & Fine sand & $\begin{array}{c}\text { Tail silty } \\
\text { sand }\end{array}$ & $\begin{array}{c}\text { Tail silty } \\
\text { soil }\end{array}$ & $\begin{array}{c}\text { Strongly weathered } \\
\text { rock }\end{array}$ \\
\hline $\begin{array}{l}\text { Permeability } \\
\text { Coefficient } \mathrm{k}[\mathrm{cm} / \mathrm{s}]\end{array}$ & $8 \times 10^{-4}$ & $1.3 \times 10^{-3}$ & $3.7 \times 10^{-4}$ & $1.5 \times 10^{-4}$ & $1 \times 10^{-4}$ \\
\hline
\end{tabular}

Meshing and Boundary Conditions. The triangular elements and quadrilateral element were used to analysis the tailings dam at present level,the model is divided into 2491 nodes, 2385 elements, the model grid is shown in Fig.2.

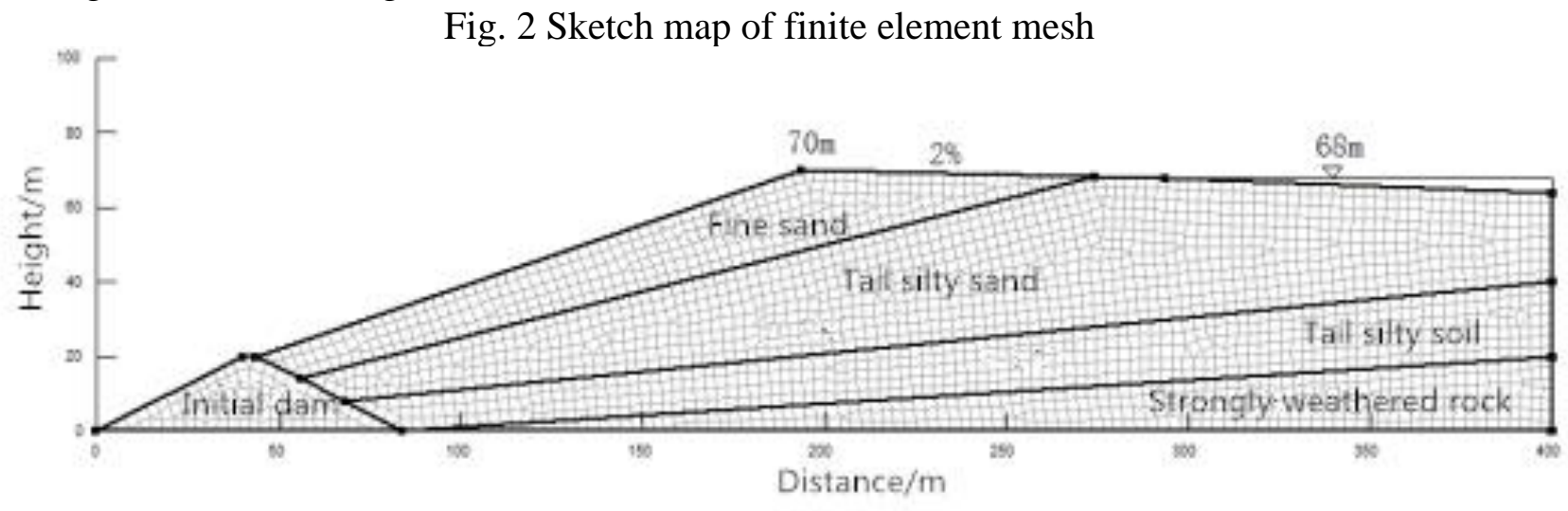

Result.Through finite element analysis to obtain the current level of infiltration line,the results as shown in Fig.3. From the analysis results, The infiltration line at the present stage does not form an overflow point on the accumulation dam, and the upper part of fill dam depth is relatively deep, reaching out to $10 \mathrm{~m}$ or more, but in the lower part of the dam near the initial dam, the depth seepage 
line is not ideal, the average depth is only $2-3 \mathrm{~m}$, when related specification stipulate the fill dam height[9] is $70 \mathrm{~m}$, the minimum depth of tailings dam infiltration line is $4.5 \mathrm{~m}$, when the dam height reaches $90 \mathrm{~m}$, the minimum depth of tailings dam infiltration line is $5.5 \mathrm{~m}$.

Fig. 3 The infiltration line at the present level

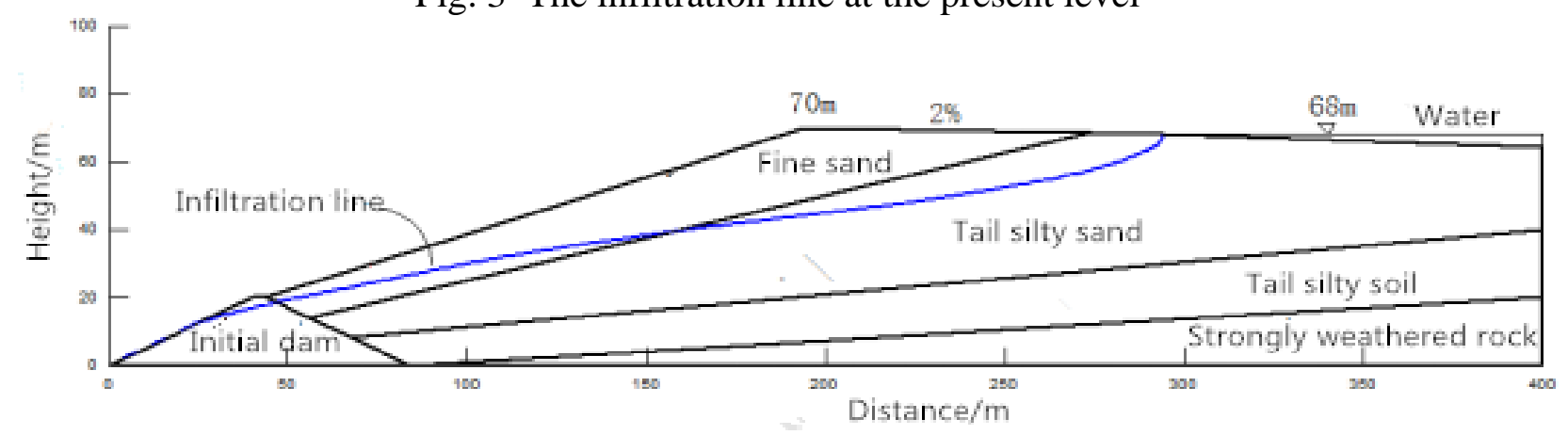

\section{The Seepage Analysis and Selection of Drainage Facilities after Increase of the Dam Height}

Seepage Analysis after Increase of the Dam Height.Zhixian Jia[10]and others studies have shown that the higher the fill dam ,the higher infiltration line under the normal water level conditions. At present, there is $20 \mathrm{~m}$ height of difference between tailings dam and the design elevation, In the process of accumulation of the dam, with the height of dam constant increase, the infiltration line is likely to overflow in the dam slope, which will bring great risk with tailings dam safety.

The triangular elements and quadrilateral element were used to simulate the tailings dam of final elevation in the finite element software,the model is divided into 2921 nodes, 2871 elements, the infiltration line is shown in Fig.4.

Fig. 4 shows when the height of fill dam reach to the design elevation, the infiltration line overflow the slope of fill dam, which pose a serious threat to the tailings dam safety, so ,in order to ensure the safety of tailings dam operation, reducing emission and controlling the depth of seepage infiltration line practical measures must to be take.

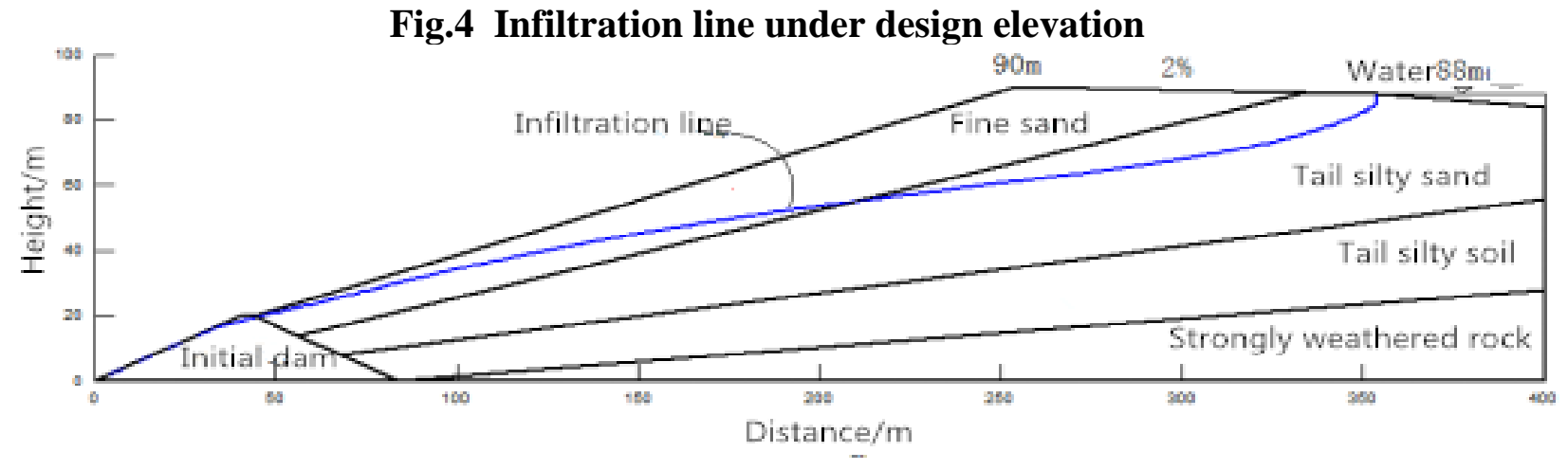

Different Drainage Facilities and Effects. There are many types of drainage installations of tailings dam, Research[11] shows that about tailings seepage failure of treatment project, generally, discharge seepage wells and wells radiation were take.

When the dam piled into the design elevation, two different drainage installations and tailings dam were designed to analysis tailings dam. At the $45 \mathrm{~m}$ height of the fill dam elevation,the drainage measures was take, and the two well have depth of $25 \mathrm{~m}$, and an inner diameter of $3 \mathrm{~m}$. For radiation tubes, 3 layers are arranged in the downstream direction., five layers are arranged in the upstream direction, radiant tube length is $50 \mathrm{~m}$, And set the bottom as the standard, the height difference between adjacent each radiant tube is $5 \mathrm{~m}$, All radiant tubes are inclined to the discharge seepage well,the ratio of slope is $4 \%$, the two different of drainage installations effect are shown in Fig.5 and Fig.6 . 
Fig.5: The effect of drainage on the traditional drainage well

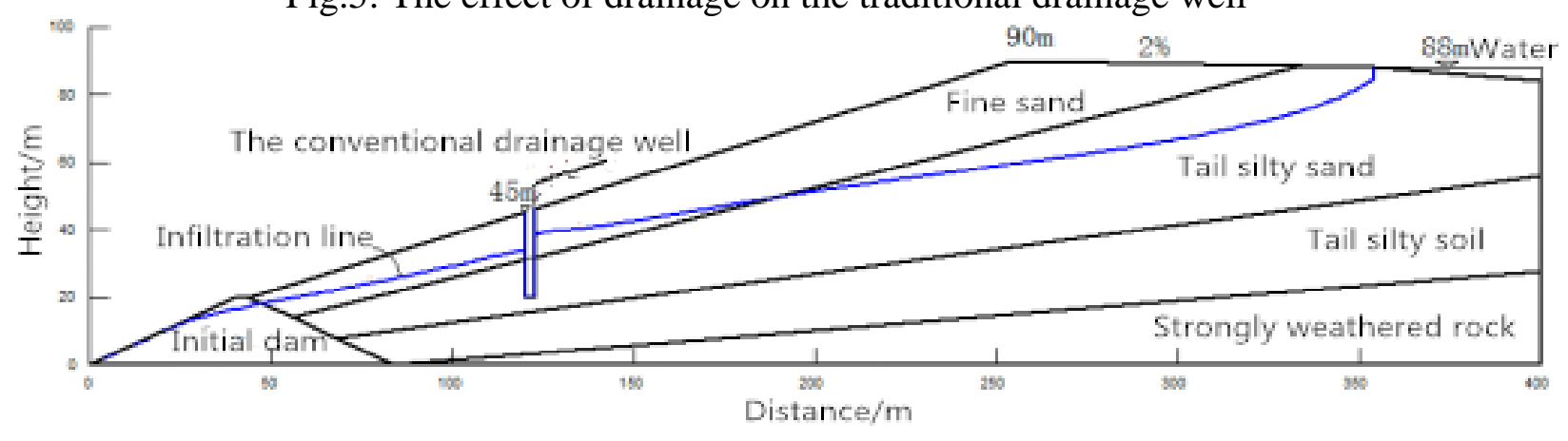

Fig.6: The effect of drainage on the radiation well

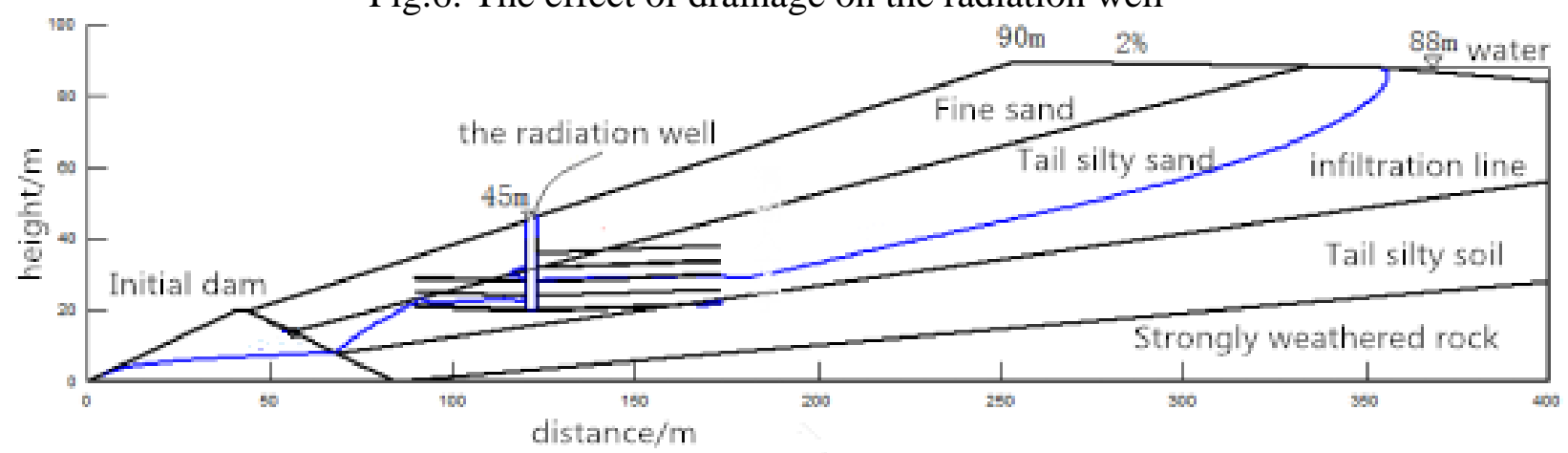

Comparative Analysis on Draining Effect.The results show when the tradition seepage wells of saturation line reduced, the reduce effect of in the downstream direction is bigger than the upstream direction, Which reason is the scope of seepage wells is not very wide, the scope of seepage wells in the upstream is larger than downstream, resulting the effect of drainage in the downstream direction is greater than upstream direction.

From the results of the analysis of the radiation well, it can be seen that the infiltration line is reduce very much, the effect is quite obvious, and the lowest buried depth has reached $12 \mathrm{M}$, far less than the minimum depth of the specification. This is because the radiation tube of the radiation well makes the scope of radiation well has increased greatly, which make the effect of the radiation well is better.

Advise.At the process of accumulation of tailings dam, the depth of infiltration line will be gradually reduced, and there may overflow from the dam of accumulation.

In the selection of emergency drainage facilities for seepage failure, the radiation well will be priority .Because radial well can not only better adapt to the geology of tailings reservoir, and have a Large water catchment range, in addition, radial well can guarantee the long-term seepage stability and have a low maintenance cost; but also the effect of seepage is obvious, radial well can make the buried depth of infiltration line has greatly reduce within a relatively short period of time, which can better and faster treat tailings seepage failure.

\section{Conclusions}

The infiltration line of tailings dam analysis is carried out under the condition of the elevation and design elevation , and the effect of conventional drainage well and the radiation well are compared, the conclusions can be obtained as follows.

1 .The elevation of the dam will make the depth of the infiltration line elevation, which may lead to the fill dam of infiltration line overflow in the process of accumulation.

2 .In order to ensure that the tailings dam will not happen seepage failure, the depth of the infiltration line of tailings dam was monitored and controlled constantly. 
3 .As far as the drainage effect is concerned, the drainage effect of the radiation well is much better than the conventional drainage well,this give priority to radiation well as emergency drainage facilities.

\section{References}

[1] Wenqi Tian, Jianguang Xue.Safety technology and management of tailing pond[M].Beijing:Coal Industry Press.2006(in Chinese).

[2] Xin Zheng,Huali Qin,Kaili Xu.Analysis of the factors inducing the tailing dam falling[J].Journal of Safety Science and Technology,2008,4(1):51-54(in Chinese).

[3] Jie Zhao,Shuying Li.Control of infiltration line of tailings dam[J].West-china Exploration Engineering,2005,(2):69-70(in Chinese).

[4] Shaojun Wang,Dingyan Ding.Three-dimensional seepage analysis of tailings dam based on MIDAS/GTS[J].Modern Mining,2015,(6):159-160,187(in Chinese).

[5] Xiaoxiao Ran,Ling Wan,Zuoan Wei.Numerical simulation and stability analysis of Yuzuzhu tailing dam by ABAQUS[J].Acta Mechanica Solida Sinica,2013,33 (S1):306-313(in Chinese).

[6] Hongde Wang,Hang Li.Effect of tailing pond starer dam drainage capacity on seepage field saturation line[J].Journal of Liaoning Technical University(Natural Science).2014,33(4):443-446(in Chinese).

[7] Hongda $\mathrm{Xu}$.The law of deposition about upstream tailings dam[J].Nonferrous Mines,2003,32(5):40-43,49(in Chinese).

[8] Zhenshi Guo,Yanqing Wu,Meili Zhan,Weihua Ding.Seepage Parameter Selection and Three-dimensional Seepage Inverse Analysis for Lixigou High Stack Dam[J].Bulletin of Soil and Water Conservation,2009,29(3):188-192(in Chinese).

[9] China Non Ferrous Metals Industry Engineering Construction Standard Specification Management Office.GB50863-2013.Code for design of tailings facilities[S].Beijing:China Planning Press.2013(in Chinese).

[10]Zhixian Jia,Mingming Yu.Seepage stability analysis of tailing dam[J].Railway Engineering,2005,(2):141-143(in Chinese).

[11]Jinhong Guo,Chenlong Huang.Type induction of drainage facilities in tailings reservoir[J].Heilongjiang Science and Technology of Water Conservancy.2014,3(42):76-79(in Chinese). 